J Am Chem Soc. 2019 June 12; 141(23): 9140-9144. doi:10.1021/jacs.9b02110.

\title{
Vinyl Carbocations Generated under Basic Conditions and Their Intramolecular C-H Insertion Reactions
}

\author{
Benjamin Wigman $^{\dagger}$, Stasik Popov ${ }^{\dagger}$, Alex L. Bagdasarian ${ }^{\dagger}$, Brian Shao ${ }^{\dagger}$, Tyler R. Benton ${ }^{\dagger}$, \\ Chloé G. Williams ${ }^{\dagger}$, Steven P. Fisher ${ }^{\ddagger}$, Vincent Lavallo ${ }^{*} \neq$, K. N. Houk ${ }^{*}, \dagger$, and Hosea M. \\ Nelson ${ }^{*} \dagger$ \\ tDepartment of Chemistry and Biochemistry, University of California, Los Angeles, California \\ 90095, United States \\ ‡Department of Chemistry, University of California, Riverside, California 92521, United States
}

\begin{abstract}
Here we report the surprising discovery that high-energy vinyl carbocations can be generated under strongly basic conditions, and that they engage in intramolecular $\mathrm{sp}^{3} \mathrm{C}-\mathrm{H}$ insertion reactions through the catalysis of weakly coordinating anion salts. This approach relies on the unconventional combination of lithium hexamethyldisilazide base and the commercially available catalyst, triphenylmethylium tetrakis(pentafluorophenyl)-borate. These reagents form a catalytically active lithium species that enables the application of vinyl cation $\mathrm{C}-\mathrm{H}$ insertion reactions to heteroatom-containing substrates.
\end{abstract}

From the lessons learned about structure and bonding arising from the great classical vs nonclassical ion debate of the mid-20th century, to the syntheses of pharmaceuticals and materials, carbocations have played a prominent role in the development of modern organic chemistry. ${ }^{1-3}$ Such electron-deficient species are typically generated under Brønsted acidic or Lewis acidic conditions, as exemplified by independent studies by Norris, Kehrmann, and Baeyer on the formation of the resonance-stabilized triphenylmethyl (trityl) cation. ${ }^{4-6}$ In the 1960s, elegant studies by Olah demonstrated that superacidic media, such as "magic acid", could be utilized to generate a variety of nonstabilized alkyl carbocations. ${ }^{7}$ Later, Reed et al. showed that, when paired with appropriately robust and weakly coordinating anions (WCAs), savagely Lewis acidic silylium ions could be utilized to access, and in some cases isolate in crystalline form, a variety of otherwise reactive carbocations. ${ }^{8,9}$ Even more reactive carbocations, such as aryl or vinyl cations, are often generated in a similar fashion and have found limited synthetic utility, save for the Balz-Schiemann and Sandmeyer reactions. ${ }^{10,11}$ While Brønsted acidic, highly oxidizing "magic acid", and potent electrophiles like silylium ions are useful in generating such reactive carbocations for the conversion of hydrocarbons, they hinder application of these strategies in the syntheses of

\footnotetext{
*Corresponding Authors: vincent.lavallo@ucr.edu, houk@chem.ucla.edu, hosea@chem.ucla.edu.

Supporting Information

The Supporting Information is available free of charge on the ACS Publications website at DOI: 10.1021/jacs.9b02110.

Procedures and characterization data (PDF)

The authors declare no competing financial interest.
} 
heteroatom-rich complex molecules, such as those utilized for materials and pharmaceuticals. ${ }^{12-14}$

Recently, aryl and vinyl carbocations have been found to undergo fast and high-yielding insertion reactions into unactivated $\mathrm{sp}^{3} \mathrm{C}-\mathrm{H}$ bonds (Figure 1a,b). ${ }^{15,16}$ In these systems the substrate scope was limited due to the electro-philicity of the silylium ion. In an effort to expand these $\mathrm{C}-\mathrm{H}$ functionalization chemistries to additional synthetic applications, we posited that tempering the Lewis acidity of our active catalytic species would greatly expand the scope of vinyl carbocation $\mathrm{C}-\mathrm{H}$ insertion reactions (Figure 1c). Here we report the discovery that high-energy vinyl carbocations can be generated under strongly basic conditions, and that they engage in intramolecular $\mathrm{sp}^{3} \mathrm{C}-\mathrm{H}$ insertion reactions through the catalysis of weakly coordinating anions. Importantly, this system features commercially available tetraaryl borate salts instead of exotic carborane salts and is demonstrated to be applicable to heteroatom-containing substrates.

Inspired by work from Michl and others, we hypothesized that Li cations, paired with WCAs, could serve as Lewis acids capable of converting vinyl triflates into reactive vinyl cations. ${ }^{17-19}$ To evaluate this hypothesis, we considered cyclooctenyl triflates (e.g., 1, Figure 2a) that undergo facile ionization by silylium cations to form vinyl carbocations. ${ }^{16}$ These cations subsequently engage in transannular $\mathrm{C}-\mathrm{H}$ insertion reactions to generate bicyclooctane products in excellent yield. We postulated that nucleophilic attack of a lithium base on $\left[\mathrm{Ph}_{3} \mathrm{C}\right]^{+}[\mathrm{WCA}]^{-}$would yield the active $[\mathrm{Li}]^{+}[\mathrm{WCA}]^{-}$catalyst (Figure $\left.2 \mathrm{a}\right) .[\mathrm{Li}]^{+}$ [WCA $]^{-}$-mediated triflate abstraction would then afford a persistent vinyl cation, $\mathbf{2}$, which would undergo transannular $\mathrm{C}-\mathrm{H}$ insertion to form bicyclic secondary cation 3 (Figure 2a). Importantly, we envisioned that deprotonation of this cation by a lithium base would generate alkene products $\mathbf{4}$ and concomitantly regenerate the active $[\mathrm{Li}]^{+}[\mathrm{WCA}]^{-}$catalyst.

To validate key elementary steps in the putative cycle, we conducted density functional theory (DFT) calculations (Figure 2b). Beginning with triflate $\mathbf{1}$ and the $[\mathrm{Li}]^{+}[\mathrm{WCA}]^{-}$ complex, using $\mathrm{HCB}_{11} \mathrm{Cl}_{11}{ }^{-}$as our WCA model, we found that $\mathrm{Li}^{+}$dissociation from the anion followed by ligation to the triflate moiety occurs with only a modest enthalpic cost, as modeled with implicit dichloromethane (DCM) solvation (5, Figure $2 \mathrm{~b}$ ). $\mathrm{Li}^{+}$ligation to the triflate while it is still coordinated to the WCA does not offer any significant energetic advantage, and subsequent triflate abstraction to provide cyclic vinyl cation 2 likely occurs with the free $\mathrm{Li}^{+}$ion. The exact role the anion plays during triflate abstraction is still being investigated, though preliminary calculations suggest that facile separation of the catalyst ion-pair is vital for generation of the vinyl cation. Once the vinyl cation is generated, the potential energy surface appears insensitive to the effects of the WCA, resulting in similar barriers and energetics using either the independent, free ions or calculating the cation(s) and WCA as tight ion-pairs. In the $\mathrm{C}-\mathrm{H}$ insertion transition state $\mathbf{T S}_{\mathbf{1}}$, complexation of the electron-deficient carbon with the $\mathrm{C} 5 \mathrm{C}-\mathrm{H}$ is followed by a favorable transannular $\mathrm{C}-\mathrm{H}$ insertion to give secondary nonclassical cation $\mathbf{6}$, which can undergo a 1,2-hydride shift to the more stable tertiary cation. Alternatively, if vinyl cation $\mathbf{2}$ is coordinated to the WCA, $\mathbf{T S}_{\mathbf{1}}$ may directly lead to either the secondary cation or the tertiary cation. Finally, either cation species can proceed via E1 elimination to form the three possible isomeric alkene products. 
Beginning with cyclooctenyl triflate $\mathbf{1}$, a screen of several Li bases, trityl salt catalysts, and general reaction conditions was undertaken. We were gratified to find that using a catalytic amount (5 mol\%) of $\left[\mathrm{Ph}_{3} \mathrm{C}\right]^{+}\left[\mathrm{HCB}_{11} \mathrm{Cl}_{11}\right]^{-}$and 1.5 equiv of LiHMDS base in $\sigma-$ difluorobenzene ( $o$-DFB) solvent produced a mixture of bicyclooctene products 4 in $4 \mathrm{~h}$, in a combined yield of $84 \%$ (Table SI-1). Remarkably, deleterious nucleophilic quenching or elimination products were not observed, despite the utilization of the highly basic hexamethyldisilazide anion in the presence of a high-energy, reactive vinyl cation intermediate. Pleasingly, commercially available $\left[\mathrm{Ph}_{3} \mathrm{C}\right]^{+}\left[\mathrm{B}\left(\mathrm{C}_{6} \mathrm{~F}_{5}\right)_{4}\right]^{-}$was superior in this reaction, providing the bicyclooctene products 4 in $98 \%$ GC yield in $30 \mathrm{~min}$ at room temperature, obviating the need for the rarer $\left[\mathrm{HCB}_{11} \mathrm{Cl}_{11}\right]^{-}$anion. Chlorinated solvents, which are traditionally unstable under silylium catalysis, ${ }^{20}$ were also competent media for these reactions, albeit providing the products in lower yield (Table SI-1). Moreover, unlike silylium-mediated reductive coupling conditions, ${ }^{15,16}$ here we generate olefinic products that can be further functionalized. ${ }^{21,22}$

While our initial studies of $\mathrm{Li}^{+}$ion-generated vinyl cations demonstrated exquisite reactivity and conversion, we sought to validate our hypothesis that the use of $\mathrm{Li}^{+}$ions would improve the substrate compatibility of vinyl cation reactions. To explore functional group tolerance, a variety of 3-arylcyclooctenyl triflates were prepared (Figure 3). We were pleased to find that the benzylmorpholine derivative underwent conversion to bicyclic styrene 7, in 42\% NMR yield after $1 \mathrm{~h}$. Similarly, heteroatom-containing thioethers and ethers were also competent under the reaction conditions $(\mathbf{8 - 1 0}, 38 \%, 38 \%$, and $60 \%$ NMR yield of the depicted olefin isomer, respectively). An electron-deficient arene was tolerated, producing styrenyl trifluoromethyl derivative 11 in 50\% NMR yield. We also found that 3-phenylcyclooctenyl triflate provided bicyclic styrene $\mathbf{1 2}$ in $46 \%$ NMR yield. The overall efficiency of the transannular C-H insertion reactions was high, with combined ca. yields of the styrenyl-, tri-, and tetra-substituted olefin isomer products ranging from $48 \%$ to $97 \%$ (Figure 3 ). ${ }^{23 \mathrm{a}}$ Isolation of each individual olefin isomer proved difficult; however, the major styrenyl product can be purified with ease. Thus, isolated yields given refer to this major product, and approximate overall yields of the olefin isomers are also given. ${ }^{23 a}$

In addition to 3-aryl-derived substrates, 2-substituted vinyl triflate $\mathbf{1 3}$ yielded silyl enol ether products 14 in $92 \%$ overall yield. These examples highlight the functional group tolerance of these newly discovered conditions, standing in stark contrast to the previously reported Lewis acid-mediated insertion reactions of vinyl cations. ${ }^{16,11,12}$ In fact, when heteroatomcontaining substrates $\mathbf{7}$ and $\mathbf{9}$ were subjected to the previously optimized silylium conditions, no reactivity was observed. ${ }^{23 \mathrm{~b}}$

Having demonstrated that cyclic vinyl triflates undergo transannular $\mathrm{C}-\mathrm{H}$ insertion reactions under Li-WCA catalysis, we sought to further expand the scope of our method to annulation reactions. Benzosuberone-derived triflates with tethered alkyl chains stood out as potential candidates for several reasons: (1) the 7-membered ring triflate would have a low barrier for vinyl cation formation, ${ }^{24}(2)$ the possibility of insertion into $1^{\circ} \mathrm{C}-\mathrm{H}$ bonds could be probed, and (3) the large number of benzosuberone derivatives that have been identified as potential therapeutics. ${ }^{25}$ Gratifyingly, upon exposure to $10 \mathrm{~mol} \%$ of $\left[\mathrm{Ph}_{3} \mathrm{C}\right]^{+}\left[\mathrm{B}\left(\mathrm{C}_{6} \mathrm{~F}_{5}\right)_{4}\right]^{-}$and 1.1 equiv of LiHMDS, propylbenzoxepinyl triflate afforded tricycle $\mathbf{1 5}$ in 84\% yield (3.3:1 
isomer ratio) after $2 \mathrm{~h}$ (Figure 4). Further, 2-substituted pinacol boronic ester, anisole, and protected aniline benzosuberone derivatives were successfully converted to their corresponding tricyclic styrene products 16-18 in 44-66\% yield. Similarly, 2-halogenated benzosuberonyl triflates provided styrene products $\mathbf{1 9 - 2 0}$ in $\mathbf{7 2 \%}$ and $82 \%$ NMR yield. Functionalization at other positions of the fused aryl system afforded tricyclic styrene products 21-24 in good to excellent yields (61-93\%). These examples not only highlight the vastly improved heteroatom compatibility of these conditions but also demonstrate the $\mathrm{C}-\mathrm{H}$ insertion reactivity of benzylic vinyl cations into $1^{\circ} \mathrm{C}-\mathrm{H}$ bonds. Finally, insertion into a benzylic $2^{\circ} \mathrm{C}-\mathrm{H}$ bond was also possible, offering styrene 25 in $76 \%$ yield.

With our scope studies in hand, we began our investigation into the mechanistic underpinnings of this transformation. Initially, because hexamethyldisilazane has been previously used as a silyl transfer reagent,${ }^{26}$ we sought to discount the formation of silylium intermediates. In this regard, we found that NaHMDS and KHMDS were not competent under standard reaction conditions, supporting our hypothesis that $\mathrm{Li}^{+}$rather than $\mathrm{Me}_{3} \mathrm{Si}^{+}$ from HMDS is the active species (Table SI-1). Instead, we attribute this discrepancy in reactivity to the enhanced Lewis acidity of $\mathrm{Li}^{+}$ions compared to $\mathrm{Na}^{+}$and $\mathrm{K}^{+}$ions, as demonstrated via Gutmann-Beckett experiments (Figure 5a). ${ }^{27,28}$ From these observations, we propose that the lithium ion is the active Lewis acid in our catalytic regime. To corroborate this mechanistic proposal, we treated triflate $\mathbf{2 6}$ with stoichiometric [Li] ${ }^{+}$ $\left[\mathrm{B}\left(\mathrm{C}_{6} \mathrm{~F}_{5}\right)_{4}\right]^{-}$, resulting in the formation of LiOTf and full consumption of the triflate starting material (Figure 5b). Notably, we also observed reduced tricycle $\mathbf{2 7}$ in $15 \%$ yield as well as other intractable mixtures of products. ${ }^{23 c}$

Additionally, we wanted to verify the in situ formation of $\mathrm{a}[\mathrm{Li}]^{+}[\mathrm{WCA}]^{-}$salt under our reaction conditions. Here we exposed $\left[\mathrm{Ph}_{3} \mathrm{C}\right]^{+}\left[\mathrm{B}\left(\mathrm{C}_{6} \mathrm{~F}_{5}\right)_{4}\right]^{-}$to 1 equiv of LiHMDS and observed rapid formation of $[\mathrm{Li}]^{+}\left[\mathrm{B}\left(\mathrm{C}_{6} \mathrm{~F}_{5}\right)_{4}\right]^{-}$by ${ }^{7} \mathrm{Li},{ }^{11} \mathrm{~B}$, and ${ }^{19} \mathrm{~F}$ NMR (Figure $5 \mathrm{c}$ ). To confirm the intermediacy of a vinyl cation species in our system, we synthesized 2phenylvinyl triflate $\mathbf{2 8}$, as 2-substituted cyclic vinyl cations have been previously reported to undergo ring-contractive rearrangement to exocyclic vinyl cations (Figure 5d) ${ }^{29,30}$ Under the reaction conditions, we observed formation of ring-contracted product $\mathbf{2 9}$ and transannular insertion product 30 . The cycloheptene derivative 29 is a result of $\mathrm{C}-\mathrm{H}$ insertion into cyclohexane from the ring-contracted exocyclic vinyl cation 31. Finally, to further validate our $\mathrm{C}-\mathrm{H}$ insertion step, we looked to disprove the possibility of 1,5-hydride migration, ${ }^{31,32}$ given the selectivity in generating five-membered rings throughout our scope studies. Exposing tert-butyl derivative $\mathbf{3 2}$ to our reaction conditions yielded cyclohexene product isomers 33 in $85 \%$ NMR yield and a 1:1 ratio (Figure 5e). These observations disfavor a 1,5-hydride migration pathway. Instead, these studies suggest a concerted (but possibly highly asynchronous) $\mathrm{C}-\mathrm{H}$ insertion mechanism, where formation of a fivemembered ring is based solely on kinetic preference.

Over 100 years after Norris, Kehrman, and Baeyer's pioneering studies on the formation of carbocations under Brønsted and Lewis acidic conditions, we show that it is possible to generate such species in highly basic media. Importantly, this catalytic regime represents a new strategy in synthetic chemistry where lithium bases can be utilized to fuel[Li] $]^{+}[\mathrm{WCA}]^{-}$catalyzed, intramolecular $\mathrm{C}-\mathrm{H}$ insertion reactions of carbocations. This study highlights the 
power of main-group-catalyzed $\mathrm{C}-\mathrm{H}$ functionalization reactions in a field dominated by transition-metal-based systems. The commercial availability of the catalyst, the simple reaction protocols described above, and the resulting vast improvement in functional group compatibility render this strategy an attractive approach to build molecules for academic as well as industrial pursuits.

\section{Supplementary Material}

Refer to Web version on PubMed Central for supplementary material.

\section{ACKNOWLEDGMENTS}

Financial support for this work was generously provided by the David and Lucile Packard Foundation (to H.M.N.), the AlfredP. Sloan Foundation (to H.M.N.), the Pew Charitable Trusts (to H.M.N), the NIH-NIGMS (R35 GM128936 to H.M.N.), and the National Science Foundation (CHE-1764328 to K.N.H., CHE-1455348 to V.L., and DGE-1650604 to S.P. and B.W.). A.L.B. and B.W. thank the Christopher S. Foote Fellowship for funding. The authors thank the UCLA Molecular Instrumentation Center for NMR and mass spectroscopy instrumentation as well as the Mass Spectrometry facility at the University of California, Irvine. Computations were performed on the Hoffman2 cluster at UCLA and the Extreme Science and Engineering Discovery Environment (XSEDE), which is supported by the NSF (OCI-1053575).

\section{REFERENCES}

(1). Olah GA 100 Years of carbocations and their significance in chemistry. J. Org. Chem 2001, 66, 5943-5957. [PubMed: 11529717]

(2). Naredla RR; Klumpp DA Contemporary carbocation chemistry: applications in organic synthesis. Chem. Rev 2013, 113, 6905-6948. [PubMed: 23819438]

(3). Olah GA; Prakash GKS; Saunders M Conclusion of the classical-nonclassical ion controversy based on the structural study of the 2-norbornyl cation. Acc. Chem. Res 1983, 16, 440-448.

(4). Norris JF On the nonexistence of trivalent carbon. Am. Chem. J 1901, 25, 117-122.

(5). Kehrmann F; Wentzel F Ueber die basischen eigenschaften des kohlenstoffs und die constitution des sogennanten triphenylmeths. Ber. Dtsch. Chem. Ges 1901, 34, 3815-3819.

(6). Baeyer A; Villiger V Dibenzalaceton und triphenylmethan. Ein beitrag zur farbtheorie. Ber. Dtsch. Chem. Ges 1902, 35, 1189-1201.

(7). Olah GA; Lukas J Stable carbonium ions. XXXIX. Formation of alkylcarbonium ions via hydride ion abstraction from alkanes in fluorosulfonic acid-antimony pentafluoride solution. Isolation of some crystalline alkylcarbonium ion salts. J. Am. Chem. Soc 1967, 89, 2227-2228.

(8). Duttwyler S; et al. C-F activation of fluorobenzene by silylium carboranes: evidence for incipient phenyl cation reactivity. Angew. Chem., Int. Ed 2010, 49, 7519-7522.

(9). Duttwyler S; et al. Synthesis and crystal structure of a silyl-stabilized allyl cation formed by disruption of an arene by a protonation-hydrosilylation sequence. Angew. Chem., Int. Ed 2009, 48, 3787-3790.

(10). Balz G; Shiemann G Ueber aromatische fluorverbindungen,I.: Ein neues verfahren zu ihrer darstellung. Ber. Dtsch. Chem. Ges. B 1927, 60, 1186-1190.

(11). Sandmeyer T Ueber die ersetzung der amidgruppe durch chlor in den artomatischen substanzen. Ber. Dtsch. Chem. Ges 1884, 17, 1633-1635.

(12). Lühmann N; Panisch R; Müller TA Catalytic C-C bond-forming reaction between aliphatic fluorohydrocarbons and arylsi-lanes. Appl. Organomet. Chem 2010, 24, 533-537.

(13). Biermann U; Koch R; Metzger JO Intramolecular concerted insertion of vinyl cations into C-H bonds: hydroalkylating cyclization of alkynes with alkyl chloroformates to give cyclopentanes. Angew. Chem., Int. Ed 2006, 45, 3076-3079.

(14). Cleary SE; Hensinger MJ; Brewer M Remote C-H insertion of vinyl cations leading to cyclopentenones. Chem. Sci 2017, 8, 6810-6814. [PubMed: 29147505] 
(15). Shao B; Bagdasarian AL; Popov S; Nelson HMN Arylation of hydrocarbons enabled by organosilicon reagents and weakly coordinating anions. Science 2017, 355, 1403-1407. [PubMed: 28360325]

(16). Popov S; et al. Teaching an old carbocation new tricks: intermolecular C-H insertion reactions of vinyl cations. Science 2018, 361, 381-387. [PubMed: 30049877]

(17). Vyakaranam K; Körbe S; Michl J Air-initiated radical polymerization of lithium salts of $\omega$ (undecamethylcarba-closododecaboran-1' ${ }^{\prime}$-yl)alk-1-enes, $\mathrm{CH}=\mathrm{CH}(\mathrm{CH} 2) \mathrm{n}-2 \mathrm{C}(\mathrm{BMe}) 11-\mathrm{Li}+$. J.Am. Chem. Soc 2006, 128, 5680-5686. [PubMed: 16637634]

(18). Vyakaranam K; Barbour JB; Michl J Li ${ }^{+}$-catalyzed radical polymerization of simple terminal alkenes. J. Am. Chem. Soc 2006, 128, 5610-5611. [PubMed: 16637608]

(19). Kitazawa Y; et al. Naked" lithium cations: strongly activated metal cations facilitated by carborane anions. J. Org. Chem 2017, 82, 1931-1935. [PubMed: 28103032]

(20). Kira M; Hino T; Sakurai H Chemistry of organosilicon compounds. 292. An NMR study of the formation of silyloxonium ions by using tetrakis[3,5-bis(trifluoromethyl)phenyl]borate as counteranion. J. Am. Chem. Soc 1992, 114, 6697-6700.

(21). McDonald RI; Liu G; Stahl SS Palladium(II)-catalyzed alkene functionalization via nucleopalladation: stereochemical pathways and enantioselective catalytic applications. Chem. Rev 2011, 111, 2981-3019. [PubMed: 21428440]

(22). Beller M; Seayad J; Tillack A; Jiao H Catalytic Markovnikov and anti-Markovnikov functionalization of alkenes and alkynes: recent developments and trends. Angew. Chem., Int. Ed 2004, 43, 3368-3398.

(23). See Supporting Information (SI) for details. (a) Crude approximate yields are given to show the overall yield of the olefinic products, determined by GC-FID or LC-MS; see SI section 3.6 for usage of the area normalization method. (b) Silylium comparison tests were also conducted to show the previous silylium conditions do not have functional group tolerance; see SI section 3.7. (c) See SI section 4.2 for details

(24). Stang PJ; Rappoport Z; Hanack M; Subramanian LR Vinyl Cations; Academic Press, 1979.

(25). Behbehani H; Dawood KM; Farghaly TA Biological evaluation of benzosuberones. Expert Opin. Ther. Pat 2018, 28, 5-29.

(26). Langer SH; Connell S; Wender I Preparation and properties of trimethylsilyl ethers and related compounds. J. Org. Chem 1958, 23, 50-58.

(27). Gutmann V Solvent effects on the reactivities of organo-metallic compounds. Coord. Chem. Rev 1976, 18, 225-255.

(28). Beckett MA; Brassington DS; Coles SJ; Hursthouse MB Lewis acidity of tris(pentafluorophenyl)borane: crystal and molecular structure of B(C6F5).OPEt3. Inorg. Chem. Commun 2000, 3, 530-533.

(29). Partch R; Margosian D 4-Homoadamanten-4-yl triflate. Ring contraction and ion pair return in trifluoroethanol. J. Am. Chem. Soc 1976, 98, 6746-6747.

(30). Pfeifer WD; et al. Behavior of bent vinyl cations generated by solvolysis of cyclic trifluoromethanesulfonates. J. Am. Chem. Soc 1971, 93, 1513-1516.

(31). Shchegolev AA; Smit VA; Kucherov VF; Caple R Acylation of acetylenes. I. Observation of an intramolecular 1,5-hydride shift in a vinyl cation intermediate. J. Am. Chem. Soc 1975, 97 , 6604-6606.

(32). Kanischev MI; Smit WA; Schegolev AA; Caple R The formation of 1,2-disubstituted adamantanes via the acylation of alkynes with 1-adamantanoyl derivatives. Tetrahedron Lett. 1978, 19, 1421-1424. 


\section{a Silylium-catalyzed $\mathrm{C}-\mathrm{H}$ insertion reactions of phenyl cations}

Shao and Bagdasarian, Science, 2017

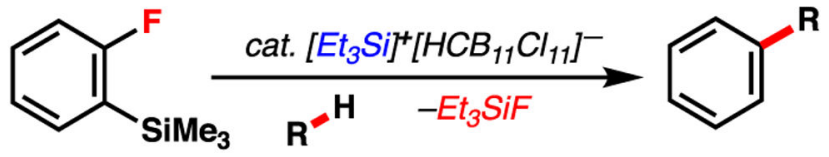

$\mathrm{R}=\mathrm{alkyl}$

b Silylium-catalyzed $\mathrm{C}-\mathrm{H}$ insertion reactions of vinyl cations

Popov, Science, 2018

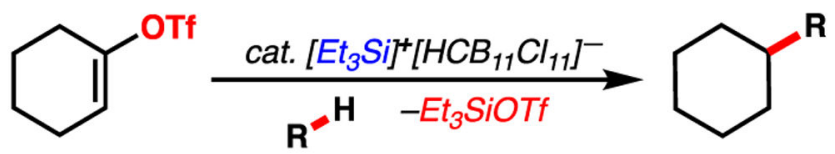

$\mathrm{R}=$ alkyl

- Hyperelectrophilic $\mathrm{Et}_{3} \mathrm{Si}^{+}$

- Rare and exotic carborane anions

-Poor substrate compatability

\section{C $\mathrm{Li}^{+}$-catalyzed $\mathrm{C}-\mathrm{H}$ insertion reactions of vinyl cations}

This research

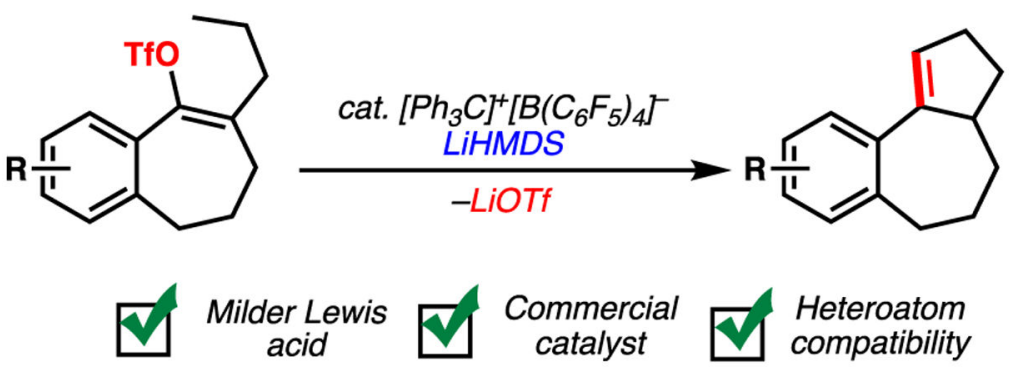

Figure 1.

Insertion reactions of di-coordinated carbocations. (a) $\mathrm{C}-\mathrm{H}$ insertion reactions of aryl cations (b) Previous $\mathrm{C}-\mathrm{H}$ insertion reactions of vinyl cations (c) $\mathrm{C}-\mathrm{H}$ insertion reactions of vinyl cations under basic conditions. 
a Proposed catalytic cycle

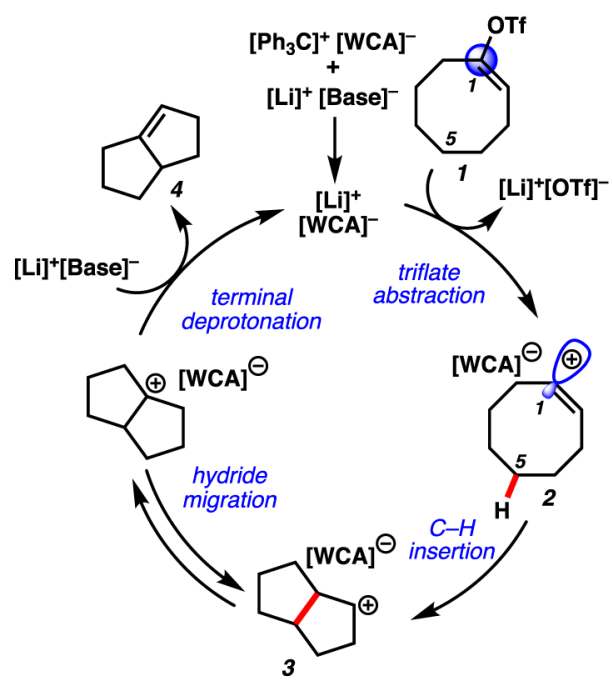

b DFT studies

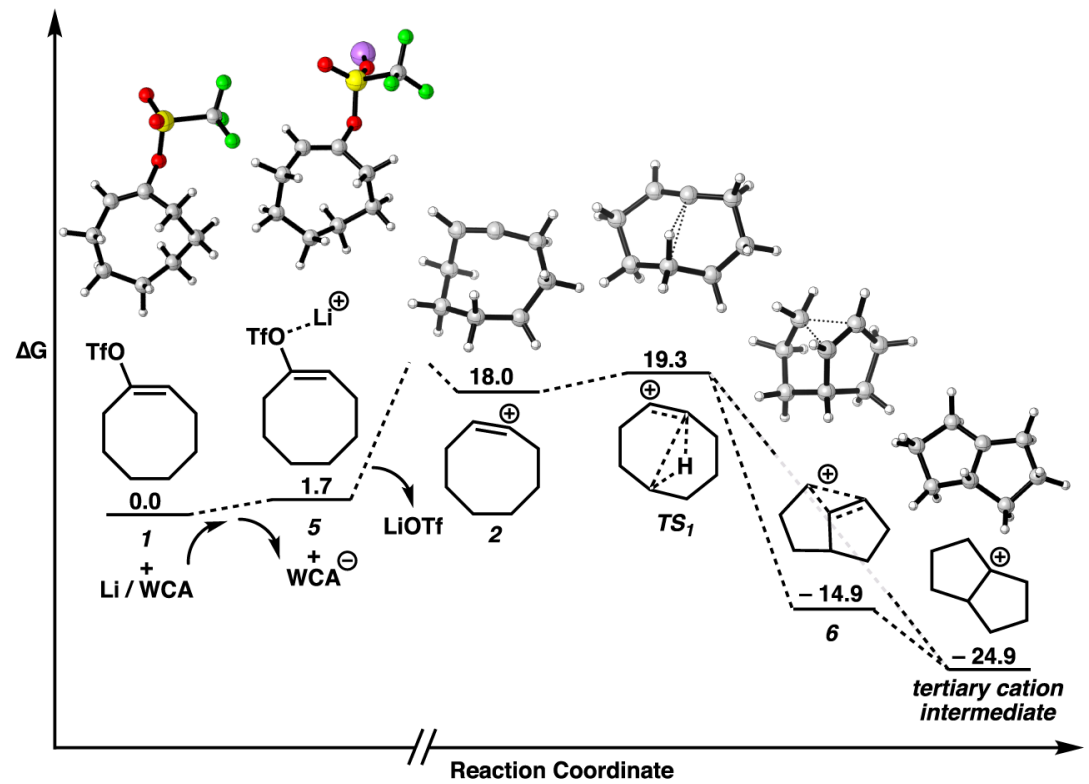

Figure 2.

Proposed mechanism for lithium-mediated intramolecular $\mathrm{C}-\mathrm{H}$ insertion reactions of vinyl cations. (a) Envisioned catalytic cycle of transannular insertion reactions of cyclooctenyl triflate 1. (b) Density functional theory (DFT) calculations supporting key mechanistic steps proposed in (a) starting from triflate 1 and $[\mathrm{Li}]^{+}[\mathrm{WCA}]^{-}$complex using $\left[\mathrm{HCB}_{11} \mathrm{Cl}_{11}\right]^{-}$as the model anion. $\Delta G$ units are reported in $\mathrm{kcal} / \mathrm{mol}$. Calculations were performed using $\omega \mathrm{B} 97 \mathrm{XD} / 6-311+\mathrm{G}(\mathrm{d}, \mathrm{p})-\mathrm{SMD}(\mathrm{DCM})$. 
a 3-aryl cyclooctenyltriflates
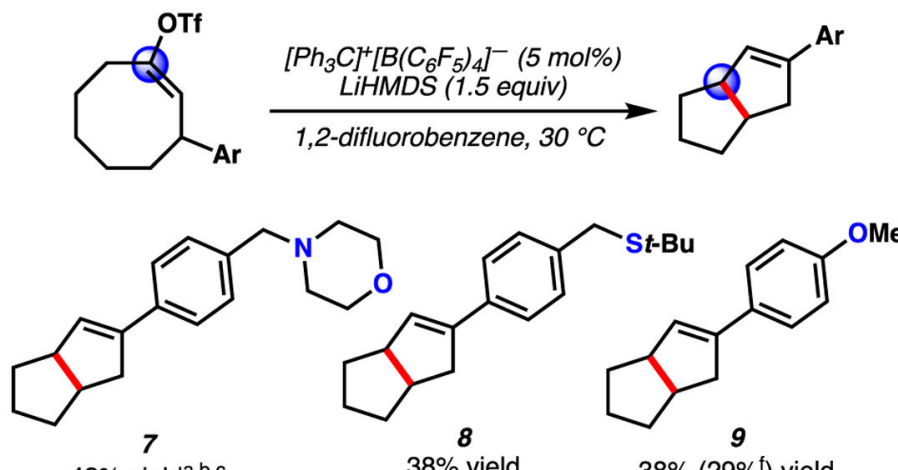

$42 \%$ yielda,b,c $^{a}$ ca. $79 \%$ yield of olefin isomers $^{d}$

$38 \%$ yield ca. $57 \%$ yield of olefin iosmers ${ }^{e}$
$38 \%\left(29 \%{ }^{\dagger}\right)$ yield ca. $48 \%$ yield of olefin iosmers $^{d}$<smiles>C1=CC(C2=CC3CCCC3C2)=CCC1</smiles>

10

$60 \%\left(46 \%{ }^{\dagger}\right)$ yield 9 $97 \%$ yield of olefin isomers

b 2-substituted cyclooctenyltriflate
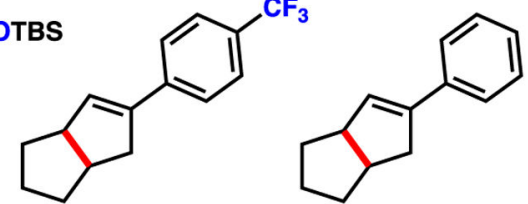

12 $46 \%\left(35 \%{ }^{f}\right)$ yield $50 \%\left(45 \%{ }^{f}\right)$ yield ca. $88 \%$ yield of olefin isomers ${ }^{d}$ ca. $75 \%$ yield of olefin isomers $^{d}$

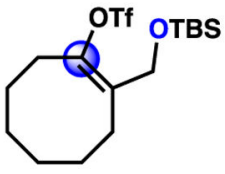

13

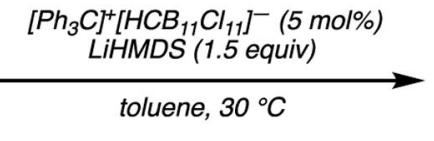

toluene, $30^{\circ} \mathrm{C}$

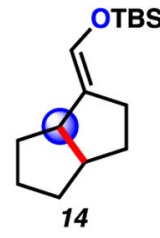

$60 \% E, 30 \% Z$ $\left(54 \%{ }^{\dagger} E, 28 \%{ }^{\dagger} Z\right)$

Figure 3.

Cyclooctenyl triflate scope. (a) $\mathrm{C}-\mathrm{H}$ insertion reactions of 3-arylcyclooctenyl triflates. (b) $\mathrm{C}-\mathrm{H}$ insertion reaction of 2-substituted vinyl triflate 13. Yields were determined by NMR using an internal standard. Conditions: ${ }^{a} 3$ equiv of LiHMDS. ${ }^{b}$ Cyclohexane as solvent. ${ }^{\circ} 70{ }^{\circ} \mathrm{C} .{ }^{d}$ Yield determined by GC-FID. ${ }^{23 a e}$ Yield determined by LCMS. ${ }^{23 \mathrm{a}} \mathrm{f}$ Isolated yield. gMethylene chloride as solvent. 


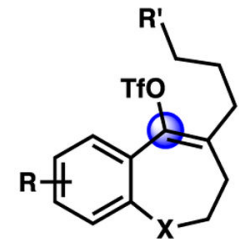

$$
X=\mathrm{O} \text { or } \mathrm{CH}_{2}
$$

$R=M e$, halide,

Bpin, p-OMePh, NMeTf

$R^{\prime}=H$ or $P h$<smiles></smiles>

15

$84 \%$ yield

(3.3:1 tetra:tri)

B

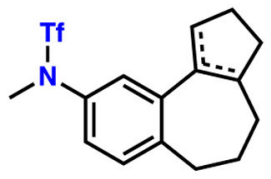

18

$66 \%$ yield

(8:1 tri:tetra)

$B$

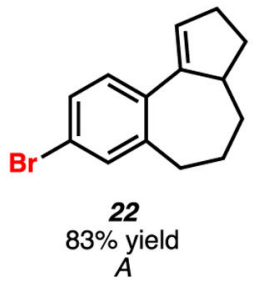

A: $\left[\mathrm{Ph}_{3} \mathrm{C}\right]^{+}\left[\mathrm{B}\left(\mathrm{C}_{6} \mathrm{~F}_{5}\right)_{4}\right]^{-}$(5 mol\%) LiHMDS (1.5 equiv) $\operatorname{DCM}(0.01 \mathrm{M}), 30^{\circ} \mathrm{C}$

B: $\left[\mathrm{Ph}_{3} \mathrm{C}\right]^{+}\left[\mathrm{B}\left(\mathrm{C}_{6} \mathrm{~F}_{5}\right)_{4}\right]^{-}(10 \mathrm{~mol} \%)$ LiHMDS (1.1 equiv) cyclohexane $(0.1 \mathrm{M}), 70^{\circ} \mathrm{C}$<smiles>[R]C1=C(c2ccccc2[X])C(CCN2CCCCC2)CC1</smiles>

$$
\text { Tf }
$$

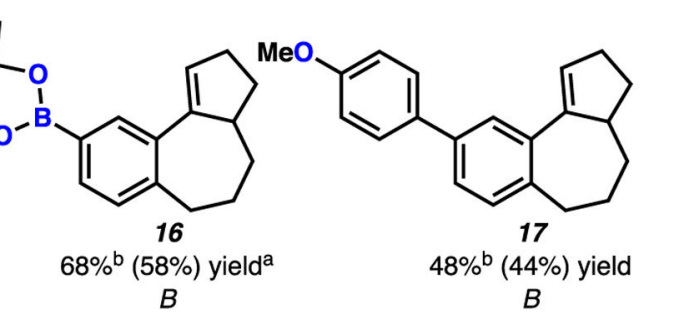

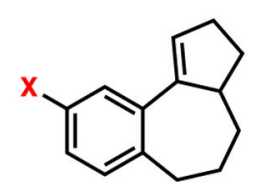

$19, X=F, 72 \%$ yield $^{b}$ 20, $\mathrm{X}=\mathrm{Cl}, 82 \%$ yield $^{\mathrm{b}}$ B

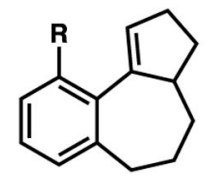

23, $\mathrm{R}=\mathrm{Me}, 7 \%^{\mathrm{b}}(61 \%)$ yield $^{\mathrm{C}}$ 24, $\mathrm{R}=\mathrm{H}, 96 \%^{\mathrm{b}}\left(93 \%^{\mathrm{d}}\right)$ yield $^{\mathrm{e}}$
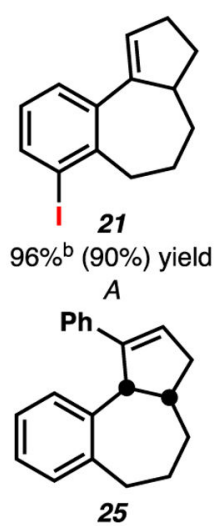

$76 \%{ }^{\dagger}$ (3.3:1 cis:trans)

Figure 4.

Benzosuberonyl triflate substrate scope. Isolated yields. Conditions: ${ }^{a} 30{ }^{\circ} \mathrm{C}$. ${ }^{b}$ Yield determined by NMR using an internal standard. ${ }^{c} 0.0167 \mathrm{M} .{ }^{d} 1 \mathrm{mmol}$ scale. ${ }^{e} 5 \mathrm{~mol} \%\left[\mathrm{Ph}_{3} \mathrm{C}\right]$

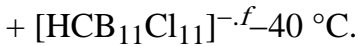


a Gutmann-Beckett ${ }^{31} \mathrm{P}$ NMR studies ${ }^{31} P$ NMR indicates relative Lewis acidity by coordination to triphenylphosphine oxide
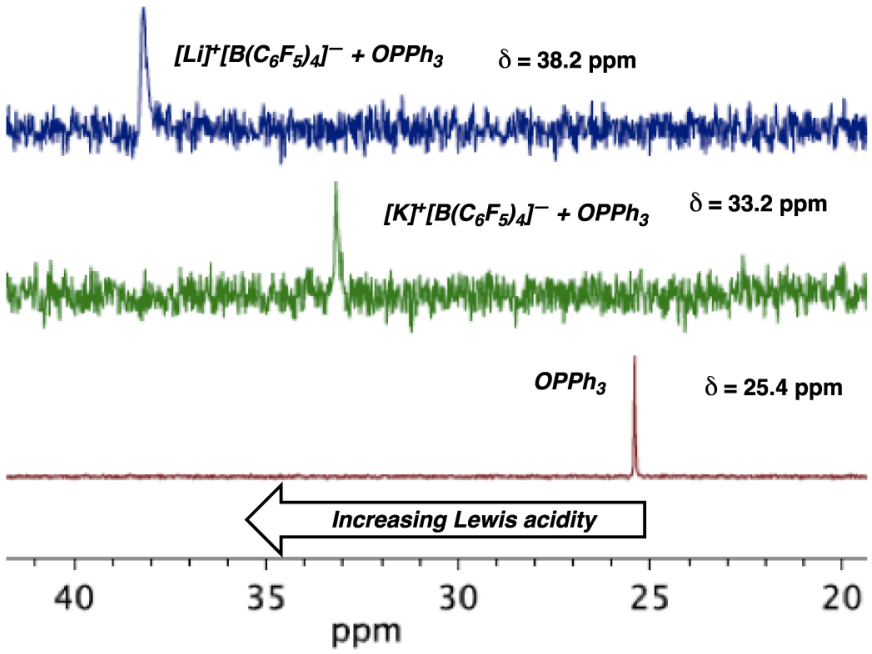

b Stoichiometric triflate abstraction

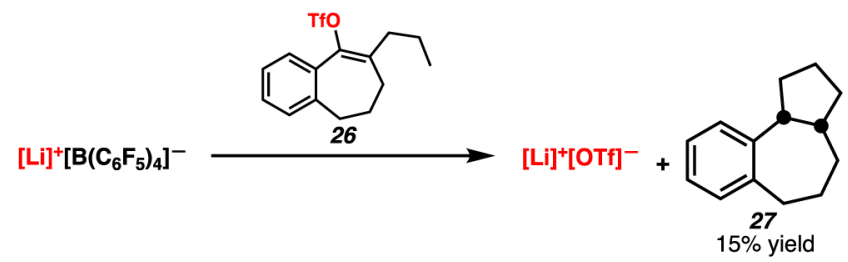

C Generation of $[\mathrm{Li}]^{+}\left[\mathrm{B}\left(\mathrm{C}_{6} \mathrm{~F}_{5}\right)_{4}\right]^{-}$under reaction conditions

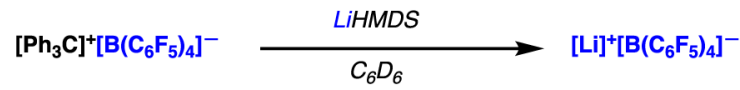

d Evidence of a vinyl cation intermediate

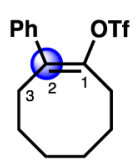

$\left[\mathrm{Ph}_{3} \mathrm{C}\right]^{+}\left[\mathrm{B}\left(\mathrm{C}_{6} \mathrm{~F}_{5}\right)_{4}\right]^{-}(5 \mathrm{~mol} \%)$ LiHMDS (1.5 equiv) cyclohexane, $70{ }^{\circ} \mathrm{C}$

28
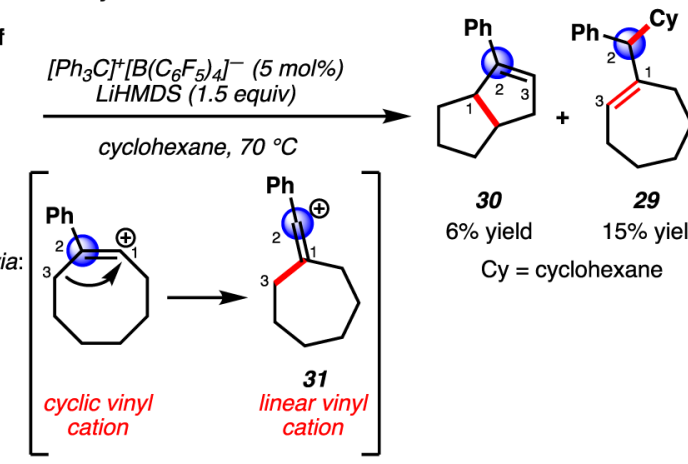

30

$6 \%$ yield $15 \%$ yield Cy = cyclohexane

e Evidence supporting concerted $\mathrm{C}-\mathrm{H}$ insertion

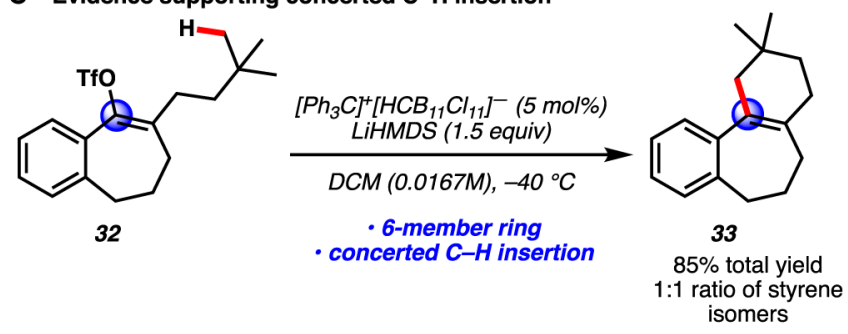

Figure 5.

Mechanistic studies of base-mediated $\mathrm{C}-\mathrm{H}$ insertion reactions. Yields were determined by NMR using an internal standard. (a) Gutmann-Beckett Lewis acidity assessment of alkali metal cations. (b) Stoichiometric triflate abstraction by $[\mathrm{Li}]^{+}\left[\mathrm{B}\left(\mathrm{C}_{6} \mathrm{~F}_{5}\right)\right]_{4}{ }^{-}$. (c) In situ formation of active catalyst. (d) Observation of ring-contracted products. (e) Formation of six-membered-ring products. 